\title{
Will metal scarcity impede routine industrial use?
}

\section{T.E. Graedel and Lorenz Erdmann}

Materials scientists today employ essentially the entire periodic table in creating modern technology. In an age of sharply increasing usage, it is reasonable to wonder about the supplies of these elemental building blocks. In this article, we review current and prospective supply and demand for a variety of metals. Although data are often sparse, available information suggests that current practices are likely to lead to scarcity for some metals in the not-too-distant future. We conclude by discussing policies that, if adopted, might defuse some of these concerns.

\section{The dynamism of metal extraction and use}

As recently as 20 or 30 years ago, designers of most manufactured products drew from a palette of a dozen or so metals. That situation has changed remarkably, as modern technology employs virtually the entire periodic table. A few examples illustrate this point: turbine-blade alloys and coatings make use of more than a dozen metals; ${ }^{1}$ thousands of components are assembled into a single notebook computer; and medical equipment, medical diagnostics, and other high-level technological products incorporate more than 70 metals. $^{2}$ This transformation is the result of the continuing search for better materials performance. To improve operational characteristics, 60 or so metals are incorporated into each microchip, ${ }^{3}$ and microchips are increasingly embedded into industrial plants, means of transportation, building equipment and appliances, consumer products, and other devices. ${ }^{4}$ It is thus increasingly important to determine whether reliable supplies of all of these metals are available, because a product designer might wish to employ a material that is not available in sufficient quantity or at a suitable price when it is needed. ${ }^{5}$

During the Industrial Revolution, vast metal deposits became accessible. Since then, wars or cartels have occasionally disrupted supplies for short periods, but the markets have always been restored over time. More recently, however, challenges to medium- or long-term supplies of a number of metals ${ }^{6,7}$ have led to increasing unease. This state of mind was reinforced in
2011 by a committee of the American Physical Society and the Materials Research Society that identified several elements, including 10 rare earth elements, as potentially critical for energy-related technologies. ${ }^{8}$

Metals, in particular, are being extracted at increasing rates (Figure 1), and end-of-life recycling rates for many of them are low to dismal. ${ }^{10}$ Moreover, for products with long service lifetimes such as turbine generators or high-speed locomotives, a stable set of materials must be available for maintenance and repair over several decades. It is therefore reasonable to ask: "Will supplies of any materials run out? If so, what and when?" In this article, we explore these questions by examining the present state of metal supply and demand, reviewing various studies of future needs, and then addressing potential limitations in response to those needs. Finally, we discuss some strategies and policies that corporations and governments might wish to consider in response to this information.

\section{Supply considerations Mining and processing}

Metals are not uniformly accessible in nature. Some metals form their own minerals, whereas some occur only in the lattices of other principal minerals (e.g., gallium in the aluminum ore bauxite). Average crustal abundance is not a good measure of overall availability, because geological processes create concentrations of individual elements or groups of elements 


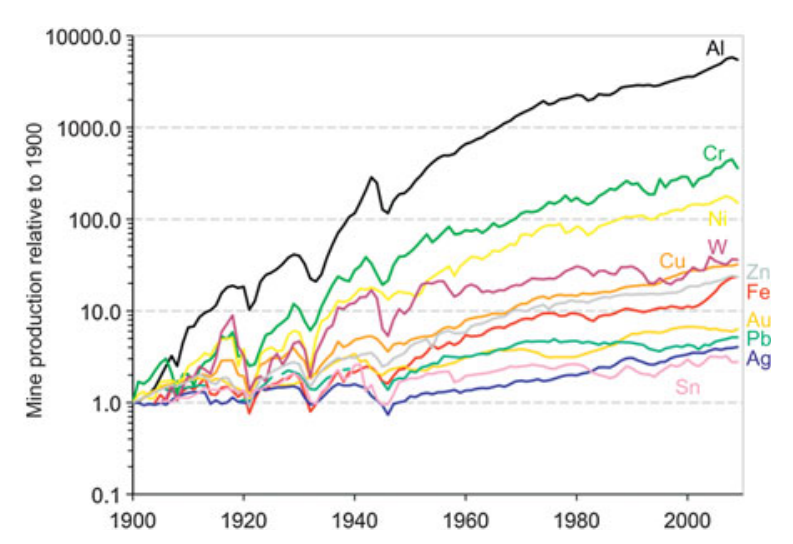

Figure 1. Relative rates of global use of materials in the 20th century. The use rate for each metal is normalized to unity in 1900. (Revised and updated from Reference 9.)

through episodic events. The deposits are dispersed geographically, and discovering them is often a challenge. For those metals that are widely used, such as lead or zinc, the occurrence and extraction potential are reasonably well known. For many of the scarcer metals, especially those brought into wide use relatively recently, information on occurrence, concentration, recovery efficiency, and so forth is often not routinely available.

Obviously, an ore body will be mined only if anticipated sales of its metals will make the venture profitable. Determining profitability in a fluctuating market is not simple, and the large investment needed to open a new mine is an ever-present barrier. Complicating the issue is the time required from discovery to production, typically a decade or more. ${ }^{11}$

\section{Companion metals}

The majority of metals in use today are not the direct target of mining, but rather are "companions" (trace constituents) in the ores of the more common metals (their "hosts"). If these companions (e.g., gallium) are to be available for use, they must be separated from their much more abundant host metals (e.g., aluminum) and then purified to a suitable (often very high) quality. The host metal's annual production value is often 100 times or more that of the byproduct metal. As a result, the value of the companion metal is unlikely to be the dominant factor in the decision to open or close a mine.

Nonetheless, much byproduct material is lost not at the mining stage but in the processing and/or refining of the ore. Over time, increased prices of the byproduct metals could encourage mining and refining companies to recover larger fractions of them rather than lose them in mine tailings, slag, or other discards.

\section{Geographical source concentration}

Mineral deposits are not equally or randomly distributed on Earth. Some minerals are predominantly found in only a few countries, whereas others have more widely dispersed ore deposits. In general, the more concentrated a mineral's deposits, the higher the risk that one or a few countries can restrict its supply. Analysis of metal reserves by the authors has identified the most geographically concentrated metals as strontium (China), the platinum group (South Africa, Russia), niobium (Brazil), tellurium (United States, Australia), and manganese (Ukraine, South Africa).

\section{Recycling}

Metals are extracted from natural deposits, processed, and then incorporated into products. When present as product constituents, the metals constitute anthropogenic metal stocks, providing the desired benefits during product in-service lifetimes. In principle, these stocks can be recovered and reused in the future, thus taking some of the pressure off virgin material supplies.

For some metals, recycling streams currently provide significant inputs to manufacturing, with lead being a prime example. Worldwide, some $80 \%$ of the lead removed from use is recycled, largely because it is predominantly employed in large amounts in relatively pure form in storage batteries that can be easily collected and processed. Copper is also widely recycled, reflecting the use of high-purity copper in such applications as power distribution and plumbing.

Such situations are unusual, however. As Figure 2 shows, most metals are primarily used in alloy form, in complex assemblages, or in uses that inherently dissipate the material. Only six metals - copper, gold, lead, platinum, palladium, and rhodium - are used predominantly in elemental form, thereby enabling recovery in that form. For nine others, including antimony and zirconium, the dominant use is dissipative, so that little or no recycling is possible. Gallium, yttrium, and 14 other metals are employed largely in complex assemblages from which recovery in elemental form is technologically very challenging and expensive. The remaining 27 elements, including molybdenum, gadolinium, and tellurium, are primarily used as alloy constituents. Even if recovered and properly identified, an alloy will likely be reused only if it or a similar alloy is needed, and the reuse will be in alloy form; the individual metals will not be recovered, meaning that their special properties in non-alloy form will be lost. The dissipation of certain metals into other recycling processes can even degrade the quality of the recycled material (e.g., the entry of copper into steel recycling from shredders).

\section{Demand}

\section{Factors affecting demand}

The single factor with the most influence on a country's demand for metals is per capita wealth, as demonstrated by Binder et al. ${ }^{32}$ in a statistical analysis of copper and zinc. The same result was found by Graedel and $\mathrm{Cao}^{33}$ for a group of seven widely used metals: chromium, copper, lead, iron, nickel, silver, and zinc. Similar studies have not been carried out for other metals, but the incorporation of so many of the elements in a wide variety of consumer products that also contain the metals that have been studied suggests that the same pattern would hold for many others. 


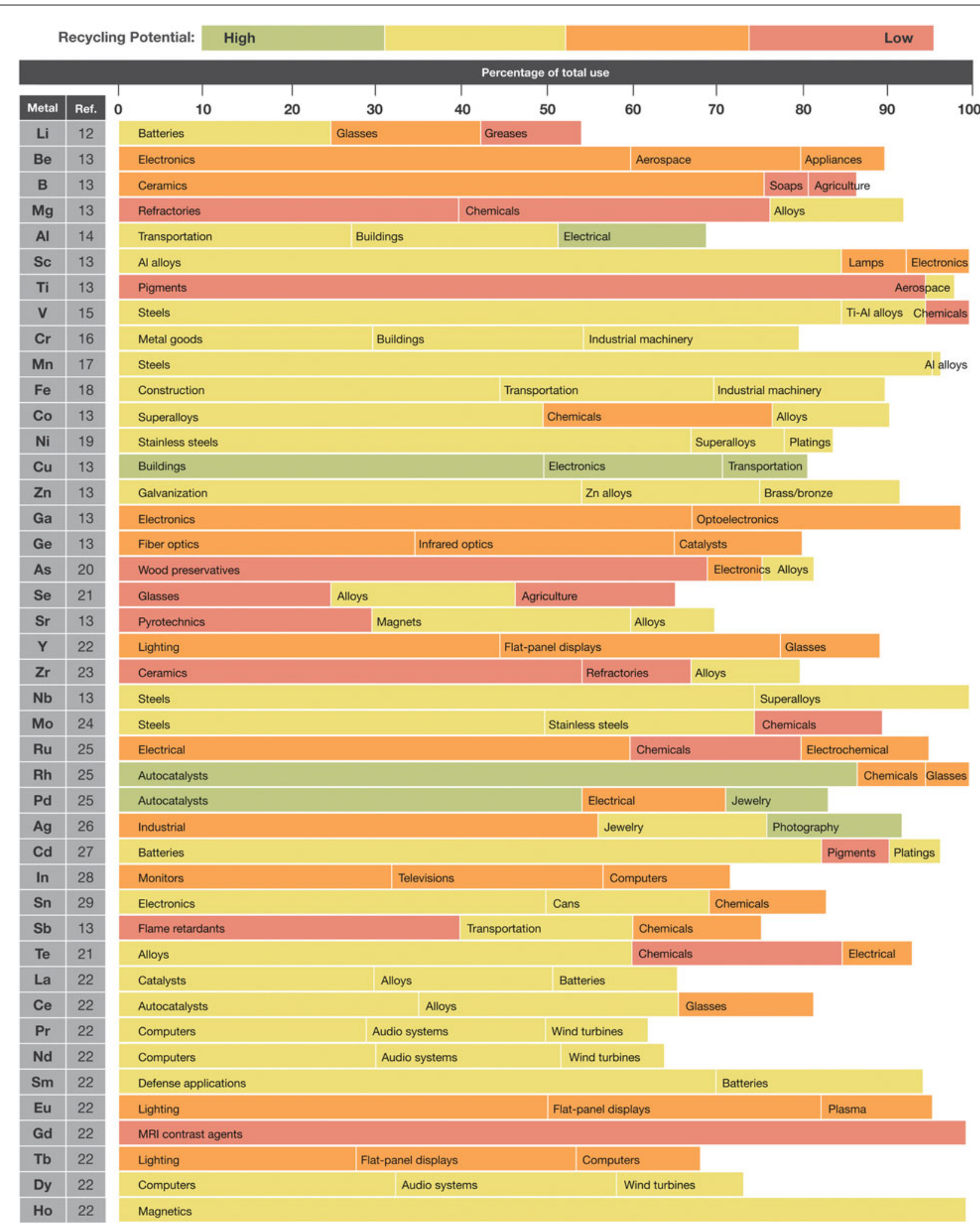

Figure 2. Principal uses and recycling potentials of selected metals. Bar length indicates the fraction of current use of the element devoted to the indicated application. Green, largely recoverable in pure form; yellow, largely in multicomponent alloy form; orange, largely in complex assemblages; red, largely in uses where the element is dispersed. 
(Figure 2 continued from previous page)

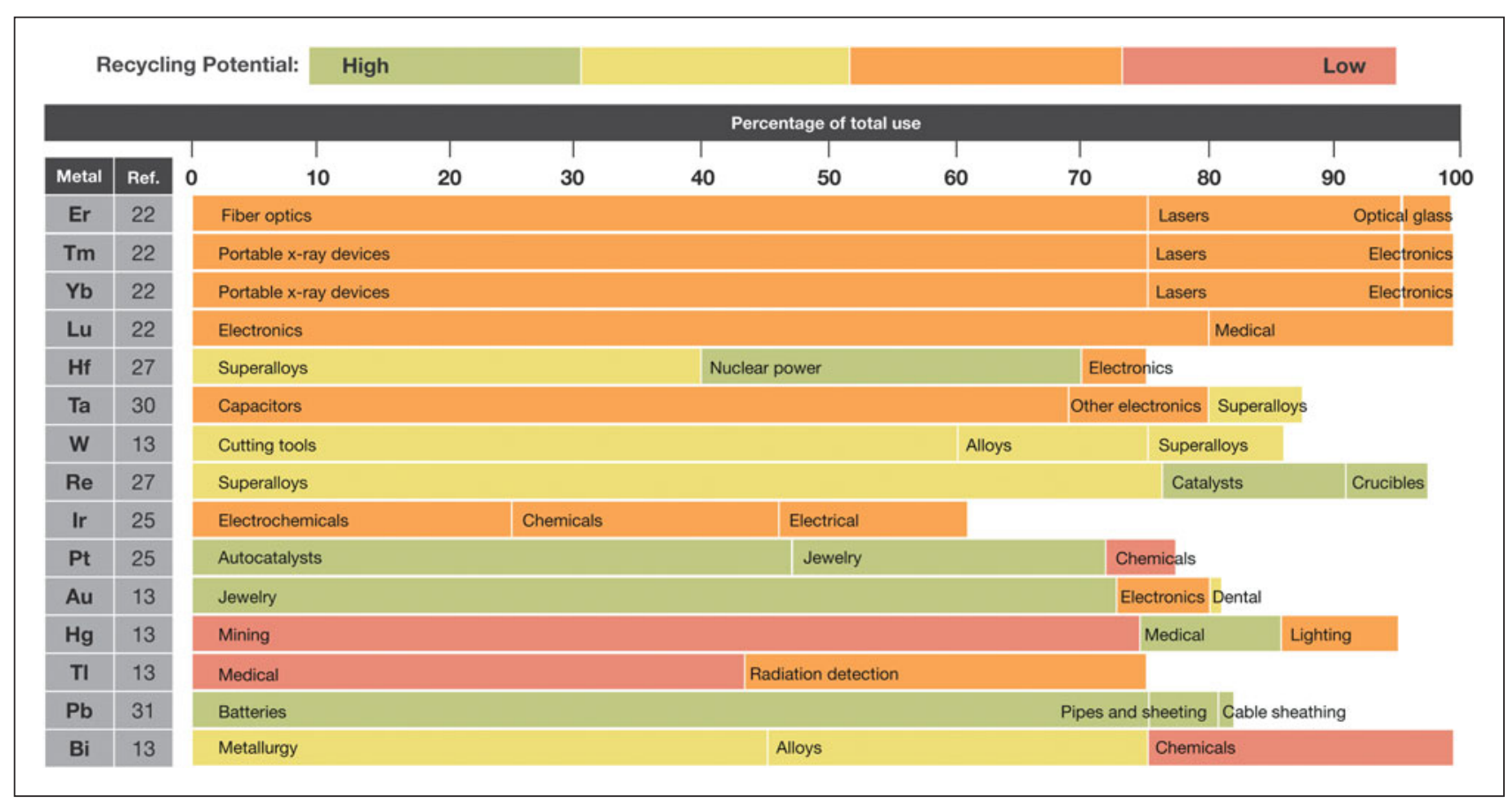

\section{Potential for substitution}

Economists often say that, if a material becomes too scarce or too highly priced, a suitable substitute will soon emerge. The actual situation is much more complicated. In today's technology, materials are selected for specific and often unique properties - emission spectrum, conductivity, electronic structure, magnetocaloric effect, and the like. In optoelectronics, for example, the central elements include gallium, germanium, tellurium, and indium. The most suitable substitutes tend to come from the same part of the periodic table, because they have similar physical and chemical properties ${ }^{34}$ However, because of those same properties, the elements generally occur together in the same ore deposits in nature. As a consequence, the most suitable substitute for a given scarce element will often experience a similar scarcity.

This is not to imply that the economic generalization is completely incorrect. Scarcity does indeed stimulate new research, and full substitution of metals can and does occur at the element, material, component, product, or functional level. However, as technology demands materials with ever more specialized properties, the challenges related to substitution will only increase, and efforts to enhance the resilience of the material supply, such as the recovery of previously used materials, should receive at least as much attention as research on substitutes.

\section{Evolutionary demand change}

With population growing and personal wealth increasing throughout the world, the historic growth in metal demand shown in Figure 1 can be expected to continue. It has been suggested $^{33,35}$ that, by mid-century, the aggregated flows of metals into use could increase by a factor of 5-10 compared to today's levels.
This evolving demand is nicely illustrated by the case of the stainless steel cycle in China in 2000 and in 2005. From an already healthy flow into use of nearly $1600 \mathrm{kt}$ of stainless steel in year 2000, the flow nearly tripled in five years. At the same time, the outflow to recycling and waste management was very small in relation, a signal that the stainless steel was seeing first use in its applications rather than replacing existing obsolete uses.

However, predictions based on per capita metal use have limits. Müller et al. ${ }^{36}$ showed that iron use appears to have reached a plateau of 8-12 t per capita in France, the United Kingdom, and the United States (Figure 3). In other countries, a plateau has yet to be reached. It is not known whether a similar pattern applies to other metals, because the data are simply not available.

\section{Transformative demand change}

Rapid changes in demand can occur if new technologies gain a market foothold and then expand rapidly. The effect can be particularly dramatic in the case of lightly used specialty materials. For example, starting in the mid-1990s, gadolinium-based compounds gained favor as contrast agents in magnetic resonance imaging. ${ }^{37}$ As medical facilities worldwide adopted these agents, the use of gadolinium increased by a factor of five within a decade (Figure 4). Similarly, indium was used in only small quantities in electrical applications until the late 1990s. The advent of flat-panel display screens with outer surface coatings of indium tin oxide, however, increased indium use by a factor of about three within a decade (Figure 5).

A study of innovative technologies that could noticeably raise future raw-materials demand was carried out by Angerer et al. ${ }^{38}$ They reported that, by 2030, the demand for several elements $(\mathrm{Cu}, \mathrm{Pd}, \mathrm{Ti}, \mathrm{Ag}, \mathrm{Ta})$ used in emerging technologies 

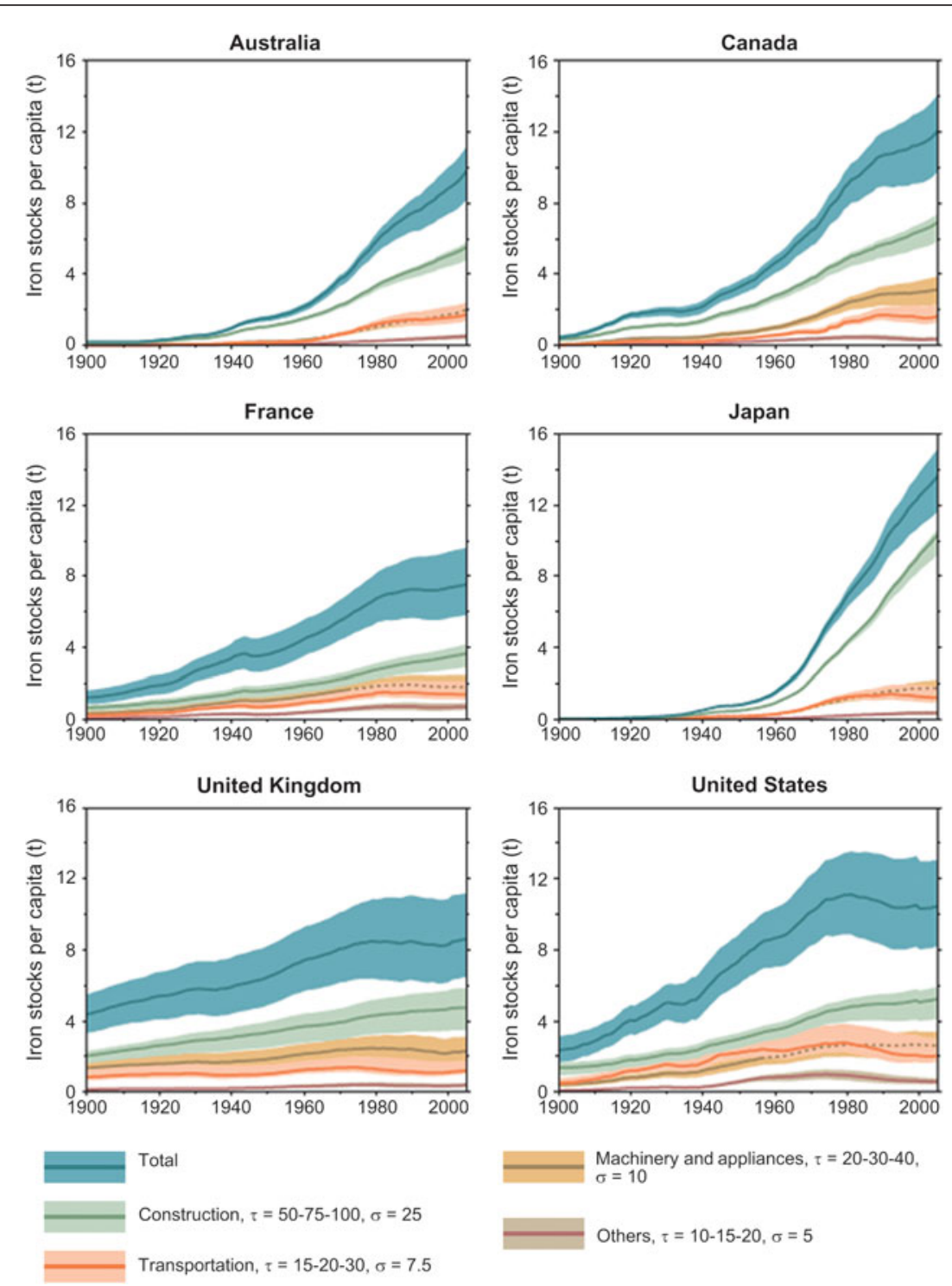

Figure 3. Total iron stocks (blue) over time in six countries, along with the decomposition of the stocks into four principal product categories. The shaded bands show the variations corresponding to the lower, middle, and upper estimates of mean product lifetimes in years, $\tau$, which span a range of $2 \sigma$, where $\sigma$ represents the standard deviation. (Reprinted with permission from Reference 36. ( 2011 , American Chemical Society.)

to predict because few complex, integrated medium- to long-term investigations have been performed. Nonetheless, the historical and prospective trends considered in the preceding sections indicate that manufacturers can no longer take adequate supplies of many materials for granted. For example, Kleijn and van der Voet ${ }^{39}$ explored the impact on resource needs if the world were to transition to a hydrogen economy based on renewable energy sources. They showed that full implementation of wind turbines, automotive fuel cells, and an expanded electrical grid would likely be impeded by inadequate supplies of neodymium, platinum, and copper. A similar situation is likely to apply to a number of other technologies and their enabling materials.

A different aspect was considered by Müller et al., ${ }^{36}$ whose analysis of iron demand in China in the 21st century is shown in Figure 6. They calculated that the use of steel for new buildings will peak in about 2035, because, by then, all Chinese should be adequately housed. Consequently, demand will then drop sharply. As buildings begin to reach the end of their usable lives, around 2050 for those built near the turn of the century, demand will again begin to rise. Some of this renewed demand, however, can be met with steel recycled from the original pulse of building a half-century earlier.

\section{Policy considerations in metal supply and demand}

If the supply of specific materials could become constrained, what are the implications for corporations? Duclos et al. ${ }^{5}$ suggested the following steps for manufacturing industries to avoid severe impacts:

- Catalog all of the materials used in the company's products. (This is a major task for firms with diffuse supply chains.)

- Develop alternative sources for all materials

was likely to increase by about a factor of three compared with 2006 levels. For several scarce specialty metals, the anticipated increases are even more dramatic: seven times for neodymium (used in high-strength magnets in wind turbines and hybridautomobile engines), eight times for germanium (fiber-optic cables) and indium (flat-panel displays), and 22 times for gallium (thin-layer photovoltaics). These are plausible projections, not certainties, but they suggest the potential for transformative technologies to transform materials demand as well.

\section{Considering the future}

The various supply and demand factors can be significantly influenced by human intervention, but the effects are hard used.

- Consider long-term supply agreements with materials suppliers.

- Improve material utilization in manufacturing.

- Develop recycling technologies for potentially constrained materials, as well as a recovery infrastructure for retrieving discarded products.

- Reduce the use of at-risk materials through product redesign and consider the use of substitute materials.

- Consider whether alternative technologies will provide satisfactory service to the customer.

Current recycling systems mainly target commodity metals such as steel, copper, and aluminum. The related recycling 


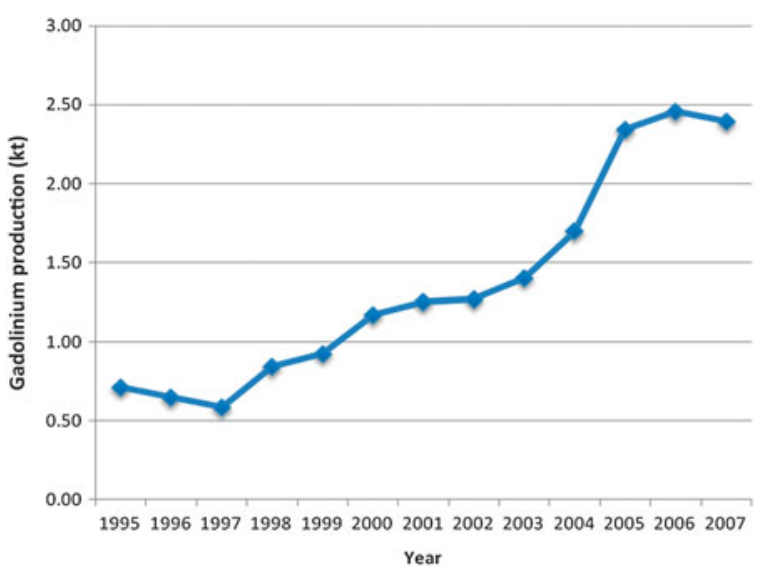

Figure 4. The rate of production of gadolinium shows a dramatic increase over the period 1995-2007. (Abstracted from Reference 22.)

processes, such as shredders for cars, were designed decades ago. However, current and future cars consist of many different materials (e.g., lithium-ion batteries, composites) that will be lost in outdated recycling processes. Thus, there is a clear need for better design for recycling (e.g., easily accessible components and easy opening of fastenings) and for new recycling processes that support the recovery of scarce metals (e.g., detection and highly efficient separation of materials) and do not pose risks of adulterating other recycling streams. In addition to automobiles, corresponding solutions are essential for buildings, electric and electronic equipment, consumer goods containing valuable materials, and other waste streams.

Just as product designers have learned to innovate under the restrictions of environmental legislation (e.g., lead-free electronics), they will adapt the design process to account for material availability and increased recycling. Better design for recycling requires cooperation with recycling companies, and accounting for materials availability might involve cooperation with other company departments, especially those responsible for procurement and disposal.

Raw-material acquisition has long been an operational activity within companies. Increasingly, raw-material supply is conceived as a strategic issue that requires risk management. Several large companies have developed strategies to increase resilience towards metal supply disruptions. For small- and medium-sized enterprises as well as entire industrial sectors, supply-chain roadmaps could provide the necessary information and timelines to decrease vulnerability.

All governments and their agencies also need to consider the possibility of supply constraints on vital materials, because no country contains within its borders the entire spectrum of resources. A typical desire is to protect the supply of materials that are vital to important domestic industries and/or to government functions, such as the manufacture and use of military hardware. A "supply-risk radar," developed in cooperation with their industries, could assist governments in monitoring and identifying potential supply risks and in launching the appropriate mitigation measures. For example, substitution for certain metals could be supported by government-funded materials research programs as part of a broader resilience strategy. Some of the suggestions above for corporate policy, such as the development of alternative sources of supply, might be appropriate at the government level as well.

\section{Conclusions}

Will the supply of metals run out? It will not do so in an economic sense, because, if a metal becomes very scarce, its price will rise, thus discouraging routine use. However, restricted use might cause opportunities, such as mass deployment of photovoltaics, to be missed. The supply of metals will also not run out in a physical sense, because metals are shifted from natural deposits to anthropogenic stocks, which can, in principle, be recycled. However, recycling of dissipated metals is restricted by related energy demand and costs.

A more insightful question is to ask whether supplies will be sufficiently constrained to impede routine industrial use. There, our conclusions are on shakier ground. Although recent attempts to classify metals as "critical" 1,42 are regarded as somewhat speculative and debatable, some general guidelines exist:

- Companion metals are riskier than host metals.

- Metals with highly concentrated sources are riskier than those with widely dispersed sources. - Metals for which recycling is difficult are riskier than those that are readily recycled.

- Metals for which emerging technologies imply major transformations in demand are riskier than those for which demand is likely to be relatively stable. 


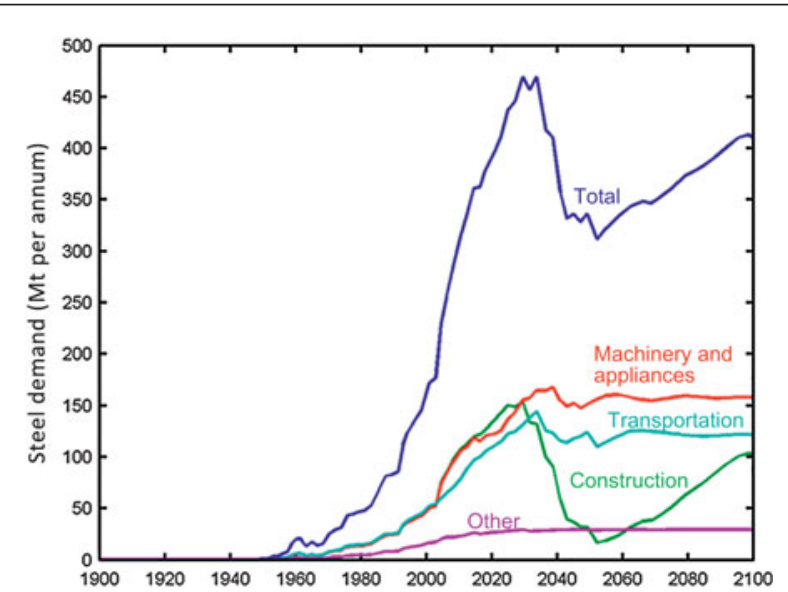

Figure 6. Historical and predicted demand for steel in China. (Courtesy of Pauliuk et al. ${ }^{40}$ )

This article provides perspectives on the supply and demand of metals and general guidelines for evaluating risk - but no firm answers. In a rapidly industrializing but finite world, the possibility for resource constraints to appear in the next few decades is very real and potentially very serious. The thoughtful materials scientist, corporate leader, or policy maker is well advised to understand the complex issue of resource supply and demand better than is now typical and to prepare for its possible eventualities.

\section{References}

1. P.W. Schilke, "Advanced Gas Turbine Materials and Coatings" (Report GER3569G, General Electric Company, Schenectady, NY, 2004).

2. S. Duclos, paper presented at Diminishing Natural Resources: Recognizing Limitations, Responding to the Challenges, Government-University-Industry Research Roundtable Meeting (sponsored by the National Academy of Sciences), Washington, DC, 20-21 October 2009.

3. Minerals, Critical Minerals, and the U.S. Economy (National Academies Press, Washington, DC, 2008).

4. L. Erdmann, L.M. Hilty, J. Ind. Ecol. 14, 824 (2010).

5. S.J. Duclos, J.P. Otto, D.G. Konitzer, Mech. Eng. 132 (9), 36 (2010).

6. M. Jacoby, Chem. Eng. News 88 (35), 9 (2010).

7. C. Krauss, New York Times B1 (10 March 2010)

8. Energy Critical Elements: Securing Materials for Emerging Technologies (Materials Research Society/American Physical Society, Washington, DC, 2011).

9. E.M. Harper, J. Johnson, T.E. Graedel, Environ. Eng. Sci. 23, 493 (2006).

10. T.E. Graedel, J. Allwood, J.-P. Birat, M. Buchert, C. Hagelüken, B.K. Reck, S.F. Sibley, G. Sonnemann, J. Ind. Ecol. 15, 355 (2011).

11. R.C. Schodde, J.M.A. Hronsky, in Wealth Creation in the Mineral Industry: Integrating Science, Business, and Education, M.D. Doggett, J.A. Parry, Eds. (Special Publication No. 12, Society of Economic Geologists, Littleton, C0, 2006), pp. 71-90.

12. SQM 2007 Annual Report (Sociedad Quimica y Minera de Chile, S.A., Santiago, Chile, 2007).

13. Mineral Commodity Summaries (U.S. Geological Survey, Reston, VA, 2010). 14. Global Aluminium Recycling: A Cornerstone of Sustainable Development (International Aluminium Association, London, 2006).

15. L. Perron, "Vanadium," in Canadian Minerals Yearbook 2001 (Natural Resources Canada, Ottawa, Canada, 2001).

16. J. Johnson, L. Schewel, T.E. Graedel, Environ. Sci. Technol. 40, 7060 (2006).

17. K. Nakajima, K. Yokoyama, T. Nagasaka, ISIJ Int. 48, 549 (2008).

18. T. Wang, D.B. Müller, T.E. Graedel, Environ. Sci. Technol. 41, 5120 (2007).

19. B.K. Reck, D.B. Müller, K. Rostkowski, T.E. Graedel, Environ. Sci. Technol. 42, 3394 (2008).

20. Minerals Yearbook (U.S. Geological Survey, Reston, VA, 2007).

21. Kirk-Othmer Encyclopedia of Chemical Technology (Wiley-Interscience, New York, 2009).
22. X. Du, T.E. Graedel, Environ. Sci. Technol. 45, 4096 (2011).

23. Mineral Sands Annual Review (TZ Mineral International, Perth, Australia, 2007).

24. "Molybdenum Uses" (International Molybdenum Association, 2010), www.imoa.info/moly_uses/molybdenum_uses.html (accessed 17 January 2011).

25. J. Butler, Platinum 2010 Interim Review (Johnson Matthey Public Limited Company, London, 2010).

26. "The Indispensable Element" (The Silver Institute, Washington, DC, 2011), www.silverinstitute.org/silver_uses.php (accessed 17 January 2011).

27. Mineral Commodity Summaries (U.S. Geological Survey, Reston, VA, 2009). 28. G.R. Matos, J.D. Jorgenson, M.W. George, Historical Statistics for Mineral and Material Commodities in the United States (USGS Data Series 140, U.S. Geological Survey, Reston, VA, 2005).

29. New ITRI Study IIlustrates the Reasons Behind Continued Boom in Tin Use (Tin Technology Limited, St. Albans, UK, 2006).

30. N. Nassar, Yale University, New Haven, CT. Private communication, 2010. 31. J.S. Mao, J. Dong, T.E. Graedel, Resour. Conserv. Recycl. 52, 1058 (2008). 32. C.R. Binder, T.E. Graedel, B. Reck, J. Ind. Ecol. 12 (1-2), 111 (2006). 33. T.E. Graedel, J. Cao, Proc. Natl. Acad. Sci. U.S.A. 107, 20905 (2010). 34. C. Hagelüken, C.E.M. Meskers, in Linkages of Sustainability, T.E. Graedel, E. van der Voet, Eds. (MIT Press, Cambridge, MA, 2010), pp. 163-187.

35. M. Hu, S. Pauliuk, T. Wang, G. Huppes, E. van der Voet, D.B. Müller, Resour. Conserv. Recycl. 54, 591 (2010).

36. D.B. Müller, T. Wang, B. Duval, Environ. Sci. Technol. 45, 182 (2011).

37. P.L. Verplanck, E.T. Furlong, J.L. Gray, P.J. Phillips, R.E. Wolf, K. Esposito, Environ. Sci. Technol. 44, 3876 (2010).

38. G. Angerer, L. Erdmann, F. Marscheider-Weidemann, M. Scharp, A. Lüllmann, V. Handke, M. Marwede, Rohstoffe für Zukunftstechnologien (Fraunhofer IRB Verlag, Karlsruhe, Germany, 2009).

39. R. Kleijn, E. van der Voet, Renewable Sustainable Energy Rev. 14, 2784 (2010). 40. S. Pauliuk, T. Wang, D.B. Müller, The future of the Chinese steel cycle, paper presented at the 2010 Gordon-Kenan Research Seminar on Industrial Ecology, New London, NH, July 10-11, 2010.

41. N. Morley, D. Eatherley, Material Security: Ensuring Resource Availability to the UK Economy (Oakedene Hollins/C-Tech Innovation Ltd., Chester, UK, 2008). 42. Critical raw materials for the EU: Report of the Ad-hoc Working Group on defining critical raw materials (European Commission, Brussels, Belgium, 2010). $\square$

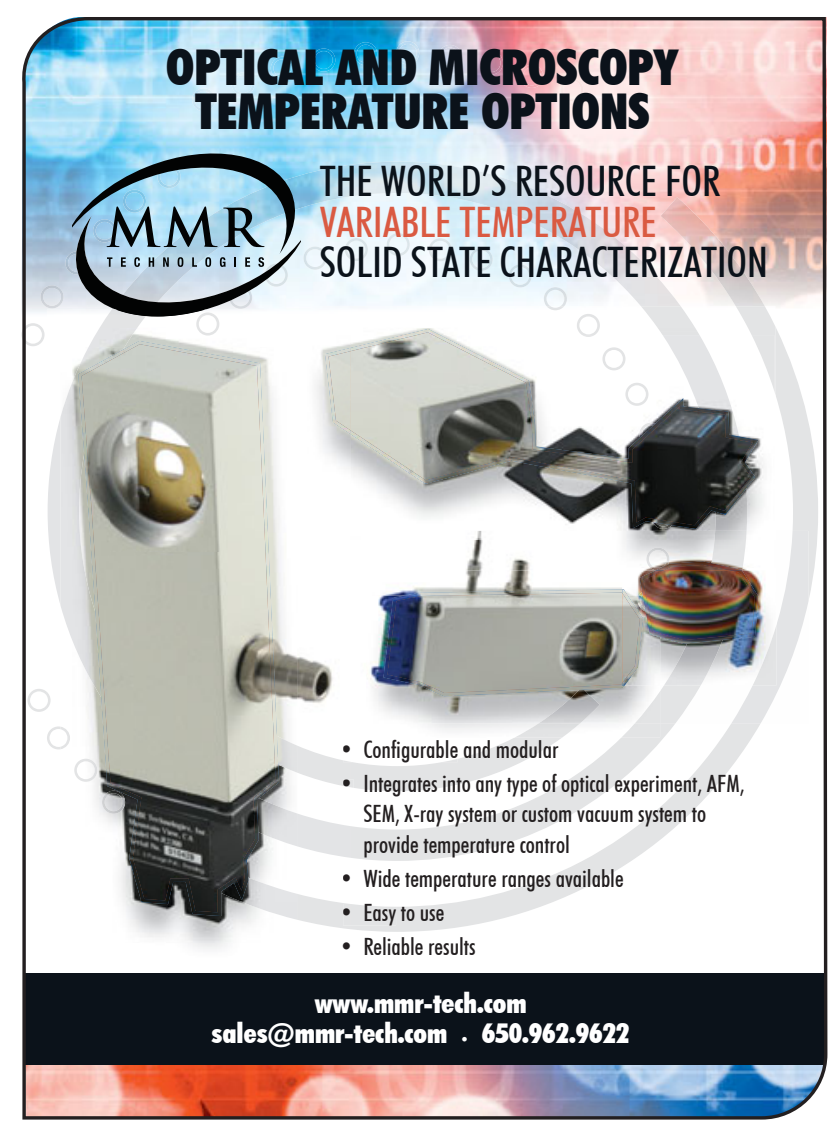


Annual Reviews offers comprehensive, timely collections of critical, topical reviews written by leading scientists. Annual Reviews journals examine 40 focused disciplines within the Biomedical, Life, Physical, and Social Sciences, including Economics. Our Editorial Committees select experienced researchers to examine and synthesize literature into concise, insightful review articles. As a result, Annual Reviews journals are among the most highly cited in scientific literature and are consistently ranked within the top ten of journals for their disciplines as indexed by the Journal Citation Reports ${ }^{\circledR}$ (Thomson Reuters).

\section{Order Today and Save $\mathbf{2 0} \%$ on ALL Annual Reviews Journals.}

Please mention priority code MRS when placing your order.

Handling and applicable sales tax additional. Order via phone, fax, or online. Institutional pricing and site license options available.

Contact Annual Reviews for details.

\section{Annual Reviews Physical Science Journals Include:}

- Annual Review of Analytical Chemistry

Volume 5 | Jul. 2012 | http://anchem.annualreviews.org

- Annual Review of Astronomy and Astrophysics

Volume 50 | Sept. 2012 | http://astro.annualreviews.org

- Annual Review of Biomedical Engineering

Volume 14 | Aug. 2012 | http://bioeng.annualreviews.org

- Annual Review of Biophysics

Volume 41 | Jun. 2012 | http://biophys.annualreviews.org

- Annual Review of Chemical and Biomolecular Engineering

Volume 3 | Jul. 2012 | http://chemeng.annualreviews.org

- Annual Review of Condensed Matter Physics

Volume 3 | Mar. 2012 | http://condmat.annualreviews.org

- Annual Review of Earth and Planetary Sciences

Volume 40 | May 2012 | http://earth.annualreviews.org
- Annual Review of Environment and Resources Volume 37 | Nov. 2012 | http://energy.annualreviews.org

- Annual Review of Fluid Mechanics Volume 44 | Jan. 2012 | http://fluid.annualreviews.org

- Annual Review of Marine Science

Volume 4 | Jan. 2012 | http://marine.annualreviews.org

- Annual Review of Materials Research

Volume 42 | Aug. 2012 | http://matsci.annualreviews.org

- Annual Review of Nuclear and Particle Science Volume 62 | Nov. 2012 | http://nucl.annualreviews.org

- Annual Review of Physical Chemistry Volume 63 | May 2012 | http://physchem.annualreviews.org

Access these and all Annual Reviews journals via your institution at www.annualreviews.org 